\title{
Cerebral palsy and criteria implicating intrapartum hypoxia in neonatal encephalopathy - an obstetric perspective for the South African setting
}

High-value claims against obstetricians in litigation in both the public and private sectors are mostly related to cerebral palsy (CP) cases on the basis of intrapartum hypoxia resulting in neonatal encephalopathy (NE) and, by extension, invoking 'negligent intrapartum care'. This development has resulted in steep rises in insurance premiums, placing service delivery under serious threat. ${ }^{[1]}$ It is widely assumed that $\mathrm{CP}$ is the direct result of an adverse event at birth and that it could have been prevented, yet only $10-14 \%$ of CP instances are caused by intrapartum hypoxia. ${ }^{[2]}$ Clinical epidemiological studies have shown that most CP cases are not related to intrapartum hypoxia. ${ }^{[3,4]}$ These studies appear, however, to be confined to high-income countries and are unlikely to be applicable to low- and middle-income countries (LMICs). South African (SA) data show that hypoxia-related deaths make up $28 \%$ of all early neonatal deaths. ${ }^{[5,6]}$

Numerous risk factors and causes are associated with $\mathrm{CP}^{[3,4]}$ We need to be careful not to oversimplify $\mathrm{CP}$, which involves complex pathophysiological processes, often juxtaposed on possible priming of the fetal brain on sometimes undetected antenatal insults. Placing this primed compromised compensated brain through the stresses of an intrapartum process could be the final straw in the pathway to brain injury and later $\mathrm{CP}$.

The literature regarding evidence for antenatal factors only, intrapartum factors only, or both, in the development of NE is mixed with lack of consistency established in work by different research groups. Cowan et al. ${ }^{[7]}$ showed that more than $90 \%$ of term infants with NE had evidence of perinatally acquired insults, with a low rate of established brain injury acquired before birth. Martinez-Biarge et al.$^{[8]}$ concluded in their study that their results did not support the hypothesis that hypoxic ischaemic encephalopathy (HIE)/NE was attributable to antepartum factors alone, and they strongly pointed to the intrapartum period as the necessary factor in the development of this condition. On the other hand, in a large study by Badawi and colleagues $^{[0]}$ investigating the presence of antenatal and intrapartum factors in infants with encephalopathy, it was concluded that, for most infants with this disorder, the causal pathway began before birth. The conflicting results between the Cowan and Badawi studies may be problematic to compare owing to differing study populations and case definitions.

The concept of fetal priming is an important one when holistically and scientifically considering causality in NE and CP. Fetal priming may play a leading role in perinatal brain injury. Antepartum priming creates a vulnerability to intrapartum stresses that may be the final straw in the pathway leading to NE. Probable priming factors are antenatal and perinatal infections, ${ }^{[10,11]}$ placental-mediated disease including the important condition of late-onset intrauterine growth restriction, ${ }^{[12-14]}$ diabetes and the fetal metabolic instability that accompanies it, ${ }^{[15-17]}$ toxic factors, maternal factors and postmaturity. ${ }^{[18-22]}$ Placental histology can identify associated placental disorders. There is enough evidence that antenatal factors could initiate a causal pathway for perinatal brain injury and that they, possibly together with genetic predispositions to hypoxic-ischaemic injury, might make some fetuses more susceptible than others to the stresses of labour and delivery. Depending on the degree of the underlying vulnerability, and depending on how soon or late the patient presents to the labour ward, the hypoxic ischaemic encephalopathic process may already be under way and, even if management of the intrapartum process is satisfactory, the syndrome of NE may not be avoidable. But whether or not a priming factor is at work, obvious findings of fetal distress in labour should be immediately dealt with. An underlying vulnerability is not an 'out' for healthcare workers who do not follow standard practice in our labour wards.

The neuro-radiological magnetic resonance imaging (MRI) terms of 'acute profound' and 'partial prolonged' brain lesions, which have found their way into the medico-legal domain, are often used retrospectively to 'diagnose' and implicate clinical events and scenarios. ${ }^{[23-27]}$ Ideally, the MRI needs to be performed within 21 days of delivery to time the cerebral insult. ${ }^{[28]}$ Timing of the insult becomes more difficult after this period. In LMICs, however, a late MRI is the norm, which may be of value as long as there is clinical correlation. If the MRI is performed beyond three weeks, it cannot on its own delineate if the injury occurred during labour or within days before labour and delivery. Imaging abnormalities suggestive of hypoxic-ischaemic injury need to be correlated, where possible, with the known sequence of events during pregnancy, childbirth and infancy. These radiological descriptions are probably accurate in describing the neurological ischaemic insult but less accurate in extrapolating this to aetiology, causation and timing, and it is doubtful that a direct extrapolation to the labouring mother in the maternity ward can always be made. Even if these lesions are seen, they may not necessarily represent events solely in the intrapartum period - in many instances, the intrapartum period is just the final straw on an already hypoxic-primed fetus from antenatal factors.

The cardiotocograph (CTG) is the cornerstone of intrapartum fetal monitoring, used for the past four decades, and is unlikely to be replaced soon. The CTG is also used frequently in the medico-legal setting to pronounce on cases. Owing to its subjective nature and large inter-observer and sometimes intra-observer variability, CTG interpretation has become a contentious issue. The CTG which has a false-positive rate for $\mathrm{CP}$ of $50-99 \%,{ }^{[29]}$ invites biased attempts by expert witnesses at retrospective temporal reconstruction of a fetal condition with the outcome known, and cannot on its own be used to determine causality. There are differing strong opinions on each side of the debate for the $\mathrm{CTG}^{[30-35]}$ and polarised views on its use intrapartum, but we believe that the answer to its use lies somewhere in the middle. We believe that introducing standardised guidelines in interpretation will improve its use and sensitivity to detect hypoxia-ischaemia. Standardised guidelines, for example those by Macones et al., ${ }^{[36]}$ will also ensure fairness in the medicolegal setting where strong personal expert opinion often wins the day rather than appropriate interpretation according to accepted criteria.

\section{Criteria for implicating intrapartum hypoxia in neonatal encephalopathy} The Cerebral Palsy Expert Task Force, which included the American College of Obstetrics and Gynaecology and the American Academy of Paediatrics in 2014, ${ }^{[28]}$ set out criteria, taking into account a broad perspective recognising numerous causal pathways to $\mathrm{CP}$, 
including a comprehensive multidimensional assessment of the neonatal status and all potential contributing factors, to establish the likelihood that an acute hypoxic-ischaemic event occurred within close temporal proximity to labour and delivery which contributed to NE. We accept these criteria and have added one more: placental histology. A summary of the criteria is presented in Fig. 1. If most of the criteria are met, this will implicate intrapartum hypoxia as causative of the CP; however, if most of the criteria are not met, then it would be unlikely that intrapartum hypoxia can be implicated in the neonatal encephalopathy or CP.

1. Case definition: Neonatal encephalopathy is a clinically defined syndrome of disturbed neurological function in the earliest days of life in an infant born at or beyond 35 weeks' gestation.

2. Apgar score: Low scores at 5 minutes and 10 minutes confer an increased relative risk of $\mathrm{CP}$ and are suggestive of intrapartum hypoxia. However, this is a subjective assessment and can often be shown to be incorrect retrospectively, based on the clinical markers entered in the case notes. Also, most infants with low Apgar scores will not develop CP.

3. Cord pH: Fetal umbilical artery $\mathrm{pH}$ $<7.0$, and/or base deficit $\geq 12 \mathrm{mmol} / \mathrm{L}$, increases the probability that neonatal encephalopathy is the result of an intrapartum hypoxic event; however, cord blood testing is often not done.

4. Presence of multisystem organ failure consistent with hypoxic-ischaemic encephalopathy: Organ dysfunction increases the likelihood of hypoxicischaemic injury in the presence of neonatal encephalopathy. It should be noted that severity of brain injury on neuroimaging may not correlate with the degree of injury to other organs.

5. Intrapartum sentinel events: Sentinel hypoxic-ischaemic events occurring shortly before delivery include, as examples, abruptio placentae, ruptured uterus and cord prolapse, as well as sudden-onset fetal bradycardia of unknown cause.

6. Fetal heart rate monitor patterns consistent with an intrapartum event Macones et al. ${ }^{[36]}$ found that Category II CTGs (indeterminate) account for $>80 \%$ of intrapartum tracings, and associated fetal acid-base status may vary from benign to threatening. Interpretation of these tracings is subjective and open to differing opinion and even biased retrospective interpretation by experts. CTGs need to be interpreted along with other clinical findings in attempts to determine causation.

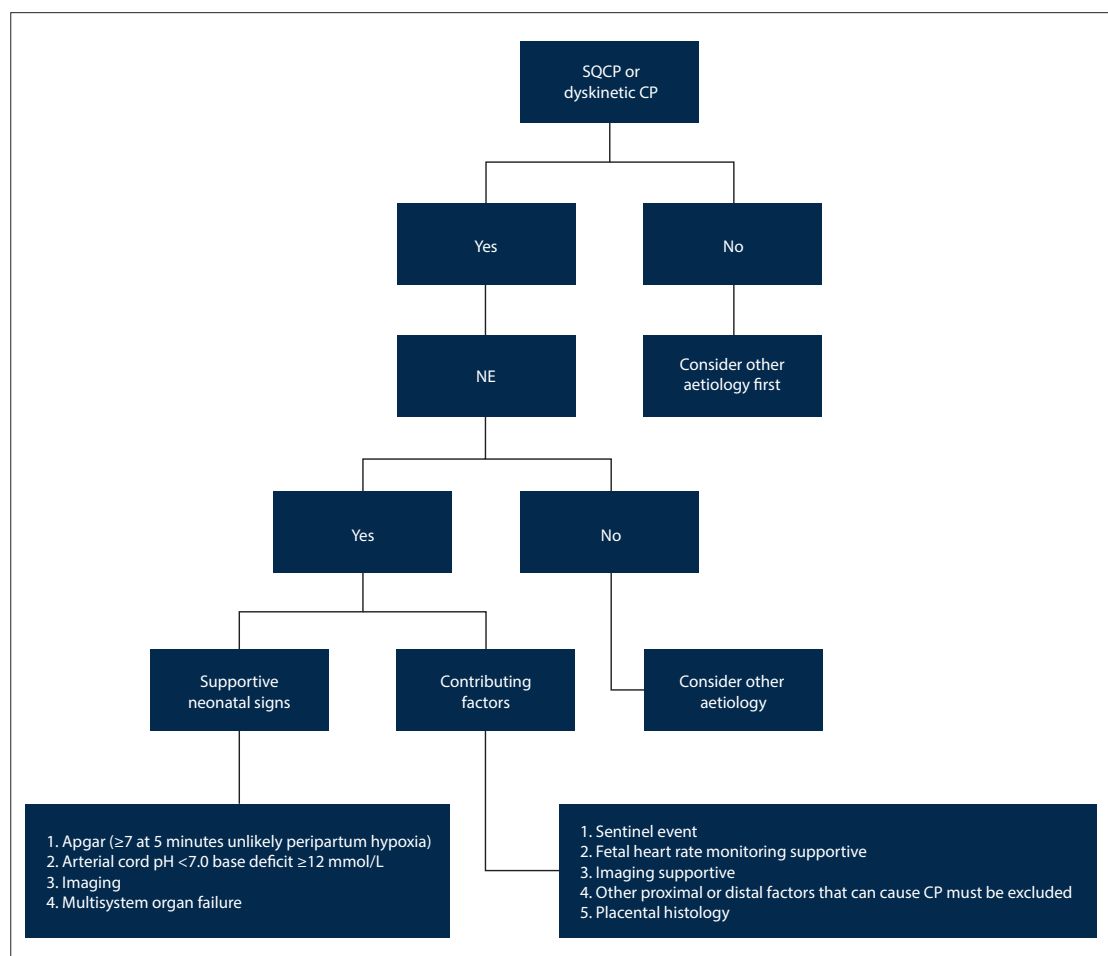

Fig. 1. Algorithm to determine if spastic quadriplegic or dyskinetic cerebral palsy may be the result of a hypoxic-ischaemic event intrapartum. ( $S Q C P=$ spastic quadriplegic cerebral palsy; $C P=$ cerebral palsy; $N E=$ neonatal encephalopathy.)

7. Neuroimaging studies - MRI: If the child's MRI is performed beyond three weeks of life, it cannot on its own delineate if the injury occurred during labour. Imaging abnormalities need to be correlated with the known sequence of events during pregnancy, childbirth and infancy. In SA, MRIs are mostly performed later in childhood, but may still be of value as long as there is clinical correlation.

8. Evidence of other proximal or distal factors: There is sufficient evidence that antenatal factors may initiate a causal pathway for perinatal brain injury and that they might make some fetuses more susceptible than others to hypoxic stresses in labour. Fetal priming may play a leading role in perinatal brain injury.

9. Developmental outcome: CP of the spastic quadriplegic or dyskinetic type is consistent with the possibility of hypoxicischaemic brain injury.

10. Placental histology: The demonstrated presence of placental disorders will assist in determining causation, given the clinical context. Currently, this investigation is not frequently requested.

\section{Conclusion}

Taking into consideration antenatal factors and fetal priming, it is simplistic to base causation of CP on only an intrapartum perspective with radiological 'confirmation', as is often the practice in medico-legal cases in SA courts. CP is a complex medical condition with numerous contributing variables and factors, and causal pathways are often difficult to delineate. Medico-legal cases involving CP in SA courts are mainly judged on MRI and CTG findings to assess causation and liability. These two modalities that retrospectively attempt to determine causation in courts are inadequate when used in isolation. Unless a holistic scientific review of the case including contributing clinical factors (antepartum, intrapartum and neonatal), fetal heart rate monitoring, MRI, and placental histology is carefully considered, success for the plaintiff or defendant in a court of law will depend on eloquent legal argument rather than true scientific causality. We offer the 10 criteria set out in this document to assist in implicating intrapartum hypoxia-ischaemia in neonatal encephalopathy as a guideline in the medico-legal setting.

Acknowledgements. We thank Profs Lut Geerts and Jack Moodley for their counsel and advice in the preparation of this manuscript. 
Author contributions. IB: Design, planning, conduct, data analysis and manuscript writing. EB: Design, data analysis, conduct and manuscript writing. P S-P: Planning, design and data analysis. EN: Planning, design and data analysis. LP: Planning, design and data analysis. IS: Design, data analysis and manuscript writing.

Funding. None.

Conflicts of interest. Prof. Bhorat is chairman of the Expert Opinion Panel for Obstetrics and Gynaecology. Prof. Buchmann does both plaintiff and defence work. Prof. Soma-Pillay does occasional defence work for the State.

\section{Bhorat}

Division of Fetal Medicine, Department of Obstetrics and Gynaecology, University of KwaZulu-Natal, Durban, South Africa ismail@iebhorat.co.za

\section{E Buchmann}

Department of Obstetrics and Gynaecology, University of the Witwatersrand, Johannesburg, South Africa

\section{P Soma-Pillay}

Department of Obstetrics and Gynaecology, University of Pretoria, South Africa

\section{E Nicolaou}

Division of Maternal and Fetal Medicine, University of the Witwatersrand, Johannesburg, South Africa

\section{Pistorius}

Division of Fetal Medicine, Stellenbosch University, Cape Town, South Africa

\section{Smuts}

Paediatric Neurology Unit, University of Pretoria, South Africa

1. Sartwelle TP, Johnston JC. Cerebral palsy litigation: Change course or abandon ship. J Child Neurol 2015;30(7):828-841. https://doi.org/10.1177/0883073814543306

2. Jacobsson B, Hagberg G. Antenatal risk factors for cerebral palsy. Best Pract Res Clin Obstet Gynaecol 2004;18(3):425-436. https://doi.org/10.1016/j.bpobgyn.2004.02.011

3. McIntyre S, Taitz D, Keogh J, Goldsmith S, Badawi N, Blair E. A systematic review of risk factors for cerebral palsy in children born at term in developed countries. Dev Med Child Neurol 2013;55(6):499508. https://doi.org/10.1111/dmcn.12017

4. MacLennan AH, Thompson SC, Gecz J. Cerebral palsy: Causes, pathways, and the role of genetic variants. Am J Obstet Gynecol 2015;213(6):779-788. https://doi.org/10.1016/j.ajog.2015.05.034 5. Pattinson R, Rhoda N. Saving babies 2012 - 2013. Ninth report on perinatal care in South Africa. http// www.ppip.co.za/wp-content/uploads/saving babies -2012-2013.

6. Mahlaba N, Nakwa FL, Rodda JR. A descriptive study of children with cerebral palsy at Chris Hani Baragwanath Academic Hospital. S Afr J Child Health 2020;14(1):4-9. https://doi.org/SAJCH.2020. v14.i1.1516

7. Cowan F, Rutherford M, Groenendaal F, et al. Origin and timing of brain lesions in term infants with neonatal encephalopathy. Lancet 2003;361(9359):736-742. https://doi.org/10.1016/S01406736(03)12658-X

8. Martinez-Biarge M, Diez-Sebastian J, Wusthoff CJ, et al. Antepartum and intrapartum factors preceding neonatal hypoxic-ischemic encephalopathy. Pediatrics 2013;132(4):e952-959. https://doi. org/10.1542/peds.2013-0511
9. Badawi N, Kurinczuk JJ, Keogh JM, et al. Intrapartum risk factors for newborn encephalopathy: The Western Australian case-control study. BMJ 1998;317(7172):1554-1558. https://doi.org/10.1136 bmj.317.7172.1554.

10. Nelson KB, Grether JK. Maternal infection and cerebral palsy in infants of normal birth weight. JAMA 1997;278:207-211.

11. Wu YW, Escobar GJ, Grether JK, et al. Chorioamnionitis and cerebral palsy in term and near term infants. JAMA 2003;290:2677-2684. https://doi.org/10.1001/jama.290.20.2677

12. Figueras F, Gratacos E. Update on the diagnosis and classification of fetal growth restriction and proposal of a stage based management protocol. Fetal Diagn Ther 2014;36:86-98. https://doi. org $/ 10.1159 / 000357592$

13. Figueras F, Caradeux J, Crispi F, et al. Diagnosis and surveillance of late onset fetal growth restriction. Am J ObstetGynecol 2018;218(2):S790-S802. https://doi.org/10.1016/.j.ajog.2017.12.003

14. Khalil A, Morales-Rosello J, Townsens R, et al. Value of third trimester cerebroplacental ratio and uterine artery Doppler indices as predictors of stillbirth and perinatal loss. Ultrasound Obstet Gynecol 2016;47(1):74-80. https://doi.org/10.1002/uog.15729

15. Bhorat IE, Bagratee J, Pillay M, Reddy T. Use of the myocardial performance index as a prognostic indicator of adverse fetal outcome in poorly controlled gestational diabetic pregnancies. Pren Diag 2014;34(13):1301-1306. https://doi.org/10.1002/pd.4471

16. Bhorat I, Foolchand S, Reddy T. Cardiac Doppler in poorly controlled gestational diabetics and its link to markers of hypoxia and adverse outcome. J Obstetrics Gynaecol 2020;41(1):66-72. https://doi.org 10.1080/01443615.2019.1710480

17. Green DW, Mimouni G. Nucleated erythrocytes in healthy infants and in infants of diabetic mothers. J Pediatr 1990;166:129-131. https://doi.org/10.1016/s0022-3476(05)81662-2

18. Guerri C. Neuroanatomical and neurophysiological mechanisms involved in central nervous system dysfunction induced by prenatal alcohol exposure. Alcohol Clin Exp Res 2002;22:304-312. https://doi. org/10.1111/j.1530-0277.1998.tb03653.x

19. Adde-Michael C, Hennebert O, Laudenbach V, et al. Effect of perinatal alcohol exposure in ibotenic acid induced excitotoxic cortical lesions in newborn hamsters. Pediatr Resc 2005;57:287-293. https:// doi.org/10.1203/01.PDR.0000148712.30716.9D

20. Bolanos JP, Medina JM. Effect of valproate on the metabolism of the central nervous system. Life Sci 1997;60:1933-1942. https://doi.org/10.1016/s0024-3205(96)00687-x

21. Nelson KB. Causative factors in cerebral palsy. Clin Obstet Gynecol 2008;51:749-762. https://doi. org/10.1097/grf.0b013e318187087c

22. Calkavur S, Akisu M, Olukman O, et al. Genetic factors that influence short term neurodevelopmental outcome in term hypoxic-ischaemic encephalopathic neonates. J Int Med Res 2011;39:1744-1756. https://doi.org/10.1177/147323001103900517

23. Barkovich J, Westmark K, Partridge C, et al. Perinatal asphyxia. MR findings in the first 10 days. Am J Neuroradiol 1995;16(3);427-438

24. Pasternak JF, Gorey MT. The syndrome of acute near-total intrauterine asphyxia in the term infant. Pediatr Neurol 1998;18:391-398. https://doi.org/10.1016/s0887-8994(98)00002-2

25. Rennie J, Rosenbloom L. How long have we got to take the baby out. A review of the effects of acute profound intrapartum hypoxia. Obstet Gynae 2011;13:169-174. https://doi.org/10.1576/ toag. 13.3 .169 .27669

26. Okumura A, Hayakawa F, Kato T, et al. Bilateral basal ganglia-thalamic lesions subsequent to prolonged fetal bradycardia. Early Hum Dev 2000;58:111-118

27. Misser SK, Barkovich AJ, Lotz JW, Archery M. A pictorial review of the pathophysiology and classification of the magnetic resonance imaging patterns of perinatal term hypoxic ischemic brain injury - what the radiologist needs to know. S Afr J Radiol 2020;24:a1915

28. Report of the American College of Obstetricians and Gynaecologists Task Force on Neonata Encephalopathy. Neonatal Encephalopathy and Neurological Outcome. 2nd ed. Obstet Gynecol 2014;123(4):896-901. https://doi.org/10.1097/01.AOG.0000445580.65983.d2

29. Nelson KB, Sartwelle TP, Rouse DJ. Electronic fetal monitoring, cerebral palsy and caesarean section: Assumptions vs evidence. BMJ 2016;355:i6405. https://doi.org/10.1136/bmj.i6405

30. National Institute for Health and Care Excellence (NICE). Intrapartum care for healthy women and babies (CG190). London: NICE, 2014. https://www.nice.org.uk/guidance/cg190

31. Ayres-de-Campos D, Spong CY, Chandraharan E, et al. FIGO consensus guidelines on intrapartum fetal monitoring: Cardiotocography. Int J Gynecol Obstet 2015;131:13-24. https://doi.org/10.1016/j. ijgo.2015.06.020

32. Wiznitzer M. Electronic fetal monitoring: Are we asking the correct questions? J Child Neu 2017;32(3):344-345. https://doi.org/10.1177\%2F0883073816676428

33. Chen HY, Chauhan SP, Ananth CV, Vintzileos AM, Abuhamad AZ. Electronic fetal heart rate monitoring and its relationship to neonatal and infant mortality in the United States. Am J Obstet Gynecol 2011;204(6):491.e1-10. https://doi.org/10.1016/j.ajog.2011.04.024

34. Vintzileos AM, Smulian JC. Decelerations, tachycardia and decreased variability: Have we overlooked the significance of longitudinal fetal heart rate changes for detecting intrapartum hypoxia? Am J Obstet Gynecol 2016;215(3):261-264. https://doi.org/10.1016/.jajog.2016.05.046

35. Toomey PC, Oppenheimer L. Prediction of hypoxic acidemia in last 2 hours of labour in low-risk women. J Obstet Gynaecol Can 2019;41(11):1564-1570. https://doi.org/10.1016/j.jogc.2018.12.015

36. Macones GA, Hankins GDV, Spong CY, Hauth J, Moore T. The 2008 National Institute of Child Health and Human Development workshop report on electronic fetal monitoring update on definitions, interpretation, and research guidelines. Obstet Gynecol 2008;112:661-666.

S Afr Med J 2021;111(3b):277-279. https://doi.org/10.7196/SAMJ.2021.v111i3b.14923 